\title{
REPERTORIUM VAN TIJDSCHRIFTLITERATUUR OP HET GEBIED VAN ACCOUNTANCY EN BEDRIJFSHUISHOUDKUNDE
}

Verschijnt maandelijks, behalve in augustus. Samengesteld door de Stichting voor Economisch Onderzoek der Universiteit van Amsterdam.

\section{A. ACCOUNTANCY}

\section{HET ACCOUNTANTSBEROEP}

L'exercice du droit de rétention par les membres de l'ordre des experts comptables et des comptables agrées

S a b a die, J e a n - Tot 1952 was het zeer twijfelachtig of de franse accountant voor het afdwingen van zijn honorarium gebruik kon maken van het recht van retentie met betrekking tot de boekhoudbescheiden van zijn client, die hij eventueel nog onder zijn berusting heeft, omdat dit recht niet strookte met de Code des Devoirs van de Ordre des Experts Comptables et des Comptables Agrées. In 1952 werd de Code des Devoirs echter op dit punt herzien, in die zin, dat aan de accountant een recht van retentie, beheerst door de regels van het gemene recht, werd toegekend: „Les membres de l'Ordre peuvent exercer le droit de rétention conformément au droit commun".

Blijkens een vonnis van de rechtbank te Rijssel past de rechter thans de rechtsregels, die voor andere tot retentie gerechtigden gelden ook toe op de accountant. De schrijver bespreekt vervolgens het recht van retentie in het franse recht en merkt op, dat de accountant, die het recht van retentie uitoefent en wiens eisen met betrekking tot het honorarium overdreven of ongemotiveerd zijn, zich aan abus de droit schuldig maakt en dientengevolge verplicht is tot schadevergoeding. Bovendien is een accountant alvorens het retentierecht uit te oefenen volgens de Code des Devoirs verplicht eerst te trachten de client over te halen tot het anvaarden van arbitrage door de Président du Conseil régional.

A II - 4

E $635.451:$ E 741.23

Revue francaise de Comptabilité, april 1961

\section{B. BEDRIJFSHUISHOUDKUNDE}

\section{a. ALGEMENE BEDRIJFSHUISHOUDKUNDE}

\section{WAARNEMINGSMIDDELEN}

\section{"Cash Flow" Analysis and Funds Statements}

$\mathrm{M}$ a s o n, Pery - Door het American Institute of Certified Public Accountants is een onderzoek ingesteld naar de vorm en inhoud van overzichten betreffende herkomst en besteding der financiële middelen. In het onderzoek werden betrokken de jaarverslagen van de 600 industriële ondernemingen welke zijn opgenomen in de uitgave 1960 van "Accounting Trends en Techniques", een jaarlijkse publikatie van het instituut.

In 190 gevallen bevatte het jaarverslag in de een of andere vorm een overzicht van herkomst en besteding der middelen. Onder middelen verstond men in 122 gevallen het werkkapitaal, in 54 de algemene financiële middelen. In 3 gevallen waren de overzichten van de middelen feitelijk cash-flow overzichten en 10 andere behoorden eveneens tot deze categorie indien courante effecten als gelijkwaardig aan kasmiddelen worden beschouwd. Het overzicht had in 110 gevallen uitsluitend betrekking op het lopende jaar, de overige 80 omvatten perioden van 2 tot 20 jaar. Slechts in 71 gevallen maakte het overzicht deel uit van de formele financiële overzichten.

Ter illustratie van de verschillen in opvatting met betrekking tot vorm en inhoud van de overzichten van de herkomst en besteding der financiële middelen zijn een 15 tal van deze overzichten weergegeven en is een aantal grafieken toegevoegd. 


\section{De geconsolideerde jaarrekening}

Hoogheid, J. C. - In dit laatste van cen serie van 5 artikelen (zie maart/aprilnummer van het repertorium) vergelijkt de schrijver de proportionele en de volledige consolidatie met elkaar. Bij de proportionele consolidatie blijkt het minderheidsbelang niet, bij de volledige consolidatic wel. Bij ingewikkelde verhoudingen is het voor de bedrijfsleiding niet meer mogelijk uit een proportioneel geconsolideerde balans de liquiditeit, solvabiliteit, rentabiliteit en kapitalisatie te beoordelen. Wat de resultatenrekening betreft zijn de bezwaren tegen proportionele consolidatie iets geringer, omdat het minderheidsbelang, dat geen evenredig aandeel heeft in de activa en passiva, wel een evenredig aandeel heeft in de resultaten. Ook hier zal echter bij volledige consolidatie het beeld duidelijker zijn.

Ba III - 3

Maandblad voor Handelswetenschappen, 1961, nr. 7.

E 771

\section{De geconsolideerde jaarrekening}

Het maart-april-nummer van het Maandblad voor Accountancy en Bedrijfshuishoudkunde is geheel gewijd aan de geconsolideerde jaarrekening. Prof. A. Goudeket stelt in een inleidend artikel dat voor een verdieping van het inzicht in deconsolidatie de aandacht in eerste aanleg gericht moet zijn op de administratieve organisatie en de berichtgeving in het algemeen. Dr. H. Veringa behandelt de administratief-organisatorische problemen rond de consolidatie en Drs. C. Zwagerman de techniek van de consolidatie en de vorm van de geconsolideerde jaarrekeningen. De juiste weergave van de resultaten der in het buitenland bedreven activiteiten worde door Prof. G. L. Groeneveld besproken in een artikel, dat als titel draagt "De valuta-problematiek in de geconsolideerde jaarrekening". Mr. C. R. C. Wijckerheld Bisdom bespreekt de vennootschapsrechtelijke positie van de geconsolideerde jaarrekening; welke positie bescheiden is: de geconsolideerde jaarrekening wordt door de wet eigenlijk genegeerd. Het nummer wordt besloten met een artikel van Drs. F. Graafstal over de geconsolideerde jaarrekening en de accountant.

Ba III - 3 Maandblad voor Accountancy en Bedrijfshuishoudkunde, maart-april 1961 E 771

\section{LEER VAN DE KOSTPRIJS EN DE PRIJSVORMING}

\section{A critical look at the marginal graph technique}

B u r chard, Joseph E. - Voor de onderneming, die naar winst streeft, is de relatie tussen kosten en produktie-omvang van grote betekenis. In de sociaal-economische literatuur wordt dit verband meestal weergegeven in een grafiek, warin de gemiddelde en marginale kostencurven worden getekend. De marginale kostencurve wordt meestal met een stijgend beloop weergegeven. In de praktijk geeft men de relatie tussen kosten en produktievolume als regel weer door middel van de break-even chart, waarin het beloop van de totale grootheden wordt weergegeven. In de break-even charts wordt bijna altijd uitgegaan van een lineair verband tussen totale variabele kosten en produktieomvang. Dit staat dus in scherpe tegenstelling tot de veronderstelling van stijgende marginale kosten, waar de sociaal-economische handbocken van uitgaan.

De auteur stelt, dat hij in zijn praktijk als accountant cen horizontaal beloop van de marginale kosten waarnam. De conceptie van de stijgende grenskosten berust op de zogenaamde wet van de niet-proportionele meer-opbrengst. Deze wet is zonder twijfel van toepassing op de agrarische produktie, maar geldt niet voor de nijverheid want daar worden geen eenheden van variabele factoren successievelijk aan een gegeven aantal eenheden van een constante factor toegevoegd. In de industrie wordt gewerkt met constante verhoudingen en de produktie wordt uitgebreid door meer van deze combinaties in gebruik te nemen. Wel is het mogelijk dat de marginale kosten stijgen in geval van overbezetting van een fabriek; dit is echter een gevolg van het in gebruik nemen van verouderde installaties, het in dienst nemen van minder efficiënte arbeidskrachten, overwerken door het personeel, enz.

Verlopen dus de marginale fabricagekosten zeker niet stijgend, wat betreft de marginale verkoopkosten is een dalend beloop zelfs plausibeler dan een stijgend beloop. 


\section{Inflation and the books of account}

What ley, R. B. - In een artikel in The Australian Accountant van juli 1960 stellen Shaw, Steins en Forrell voor om in het geval van stijging van de waarde van de duurzame produktiemiddelen en de voorraden grond-en hulpstoffen in de balans de Profit and Loss Appropriation Account voor deze waardestijging te debiteren met als tegenrekening „Price Compensation Account”. Alleen op deze wijze kan de koopkracht van het vermogen intact worden gehouden. Voorzover echter vrijgekomen afschrijvingsbedragen in activa worden gebonden, welke niet dezelfde waardestijging meemaken als de activa waarvan de vervanging eerstdaags uit deze gelden moet worden gefinancierd, is door deze methode van boekhouden de vervanging nog niet veilig gesteld. In die gevallen is nog een extra reservering vercist op de rekening "Plant Renewal Reserve".

$\mathrm{Ba}$ IV - 2e

E 136.322 .1

The Accountants' Journal, maart 1961

\section{De problematiek van de calculatie van rente en belasting in de kostprijs}

Fo p pe, H. H. M. - In aansluiting op het artikel van Prof. A. van Rietschoten „De rente in de kostprijs” in het novembernummer van het Maandblad voor Accountancy en Bedrijfshuishoudkunde van 1958 stelt de schrijver dat er welhaast communis opinio bestaat ten aanzien van de vraag of rente in de kostprijs dient te worden gecalculeerd, althans voorzover het betreft de rente over het vreemd vermogen. Ten aanzien van te calculeren rente over het eigen vermogen heerst nog meningsverschil, terwijl de fiscus weigert de rente over het eigen vermogen als fiscale last te aanvaarden.

Alle elementen van de kostprijs binden financiële middelen en veroorzaken dus rentekosten. Het rentepercentage waarmee gewerkt wordt is een gewogen gemiddelde van de aangetrokken vermogenscomponenten; m.a.w. de rentevoet die over de kostprijscomponenten moet worden berekend moet grosso modo gelijk zijn aan de verschuldigde rentevoet over de aangetrokken vermogensdelen. Bij de berekening van dit gewogen gemiddelde moet als beloning van het eigen vermogen de rentevoet worden genomen die de vermogensverschaffer eist als primaire beloning. Wat deze vermogensverschaffer als risicopremie beschouwt is onverbrekelijk an deze beloning verbonden en wordt door het bedrijf als bedrijfslast ondervonden. Bij de calculatie moet ook rekening worden gehouden met de over de rente van het eigen vermogen geheven belastingen.

Ba IV - 3

E 136.325 : E 136.341 .6

Maandschrift Economie, april 1961

\section{LEER VAN DE FINANCIERING}

\section{Some factors influencing share prices}

F is he r, G. R. - Het Department of Applied Economics van de Universiteit van Cambridge heeft een onderzoek ingesteld naar de invloed van dividenden, ingehouden winsten en grootte van de vennootschap op de koers van de aandelen van een aantal industriële ondernemingen op de Londense beurs in het tijdvak 1949-1957.

De hoogte van het laatste dividend bleek van zeer grote invloed op de koers. Als verklarende factor voor het koersniveau $\mathrm{kwam}$ in de tweede plaats de ingehouden winst. Indien er een dividendstop heerst is echter de invloed van de ingehouden winst op de koers minder sterk. Het effect van het dividend en de ingehouden winst op de koers bleek voor de onderzochte fondsen van jaar tot jaar tamelijk stabiel. Tussen bedrijfstakken liep de invloed van deze factoren op de koers enigszins uiteen, maar binnen de bedrijfstak was dit in veel mindere mate het geval. De invloed op de koers van het beloop van de dividenden in de voorafgaande jaren bleek gering. Het onderzoek wees uit, dat naast het dividend en de ingehouden winst de grootte der onderneming een niet-onbelangrijke invloed op de koers uitoefent.

E 346.1

$\mathrm{Ba} \mathrm{V}-3 \mathrm{~b}$

The Economic Journal, maart 1961

\section{The Judgment Factor in Investment Decisions}

W a Ike r, R. G. - De schrijver bespreekt de onbevredigende wijze waarop het investeringsvraagstuk veelal in het bedrijf wordt benaderd. De redenen van deze ongewenste situatie zijn: (1) de moeilijk te beoordelen onzekerheden met betrekking tot de toekomst, (2) een onvoldoende opleiding van degenen die het investeringsvraagstuk zullen moeten behandelen, (3) de neiging van de theoretische economisten om in hun uiteenzettingen de in de praktijk rijzende moeilijkheden bij het bijeenbrengen van de vereiste gegevens, te omzeilen. Vervolgens staat Walker stil bij de voornaamste fouten welke in het bedrijf worden gemaakt. In vele gevallen wordt de invloed van te schatten essentiële 
variabelen, zoals bv. de economische gebruiksduur, genegeerd of op onjuiste wijze bij het nemen van beslissingen in aanmerking genomen. Een andere fout is dat het vraagstuk niet zuiver wordt gesteld; vooral bij voorstellen tot vervanging van apparatuur komt dit dikwijls voor. Tenslotte wordt vaak te weinig andacht besteed aan het vaststellen van de minimaal vereiste rendementsgraad en aan de wijze waarop deze maatstaf moet worden gehanteerd. Zowel door sommige individuele bedrijven als door associaties van de machine-fabrikanten en door de wetenschap zijn in de Verenigde Staten belangrijke bijdragen tot beter begrip van de investeringsproblematiek geleverd. Hoewel de oplossing steeds een zaak van verstandig compromis zal blijven en het inzicht van de topleiding de beslissing zal moeten brengen, zullen de resultaten van de intensieve bestudering van dit vraagstuk in de laatste tijd daadwerkelijk het inzicht kunnen verdiepen.

$\mathrm{Ba} \mathrm{V}-7$

Harvard Business Review, maart-april 1961

E $641.26:$ E 241.4

\section{LEER VAN DE ORGANISATIE}

\section{Budgettering op basis van optimale capaciteit}

$\mathrm{B}$ os ch, Dr J., en P. J. S te e n brink - Het is weihaast een traditie geworden om bij de opbouw van het budget de variabele kosten te bepalen bij het niveau van de verwachte produktie en de vaste kosten te relateren aan de normale bezetting, dit is de bezetting, die het gemiddelde vormt van een conjunctuurcyclus. Zodoende wordt voorkomen, dat de kostprijs fluctueert met de fluctuatie van de werkelijke bezetting. Toch staat de doelmatigheid van de gevolgde methode niet zonder meer vast. De bepaling van de conjunctuurcyclus is immers tamelijk arbitrair. De schrijvers stellen daarom voor de vaste kosten te relateren aan de optimale capaciteit, aan welk begrip een scherper omlijnde inhoud kan worden gegeven. De optimale capaciteit is het produkt van optimale uren en optimale produktiviteit per uur. Bij de bepaling van het aantal optimale uren moet rekening worden gehouden met onvermijdbare verliezen in verband met reparatie, onderhoud, instellen, etc. De optimale produktiviteit per uur is de nettoopbrengst, welke in het betrokken budgetjaar bereikbaar moet worden geacht. Het is vooral de technische ontwikkeling, die de oorzaak vormt van een voortdurend optredende productiviteitsverbetering.

Het komt de schrijvers doelmatig voor om ook de variabele kosten te bepalen bij het niveau van de optimale capaciteit. In het algemeen is nl. met uitzondering van afschrijving en rente het onderscheid tussen vaste en variabele kosten vrij willekeurig.

$\mathrm{Ba}$ VI - 18

E 641.231.3

Maandblad voor Bedrïfsadministratie en -organisatie, mei 1961

\section{LEER VAN DE ARBEIDSVOORWAARDEN}

\section{Zum Problem der Ausländischen Arbeitskräfte in der Schweiz}

Het juni-nummer van Industrielle Organisation is gewijd aan het vraagstuk van de buitenlandse arbeiders. Francesco Kneschaurek ziet het als een blijvend vraagstuk voor de landen, die zich in een fase van groei bevinden. Er komt voor deze landen een moment, waarop het aantal additionele arbeidskrachten, dat nodig is om de groei onverminderd te doen voortgaan groter is dan de aanwas van de beroepsbevolking. Max Holzer bespreekt het toelatingsbeleid van Zwitserland, terwijl Peter Dürrenmatt de staatsrechtelijke positie van de vreemde arbeidskrachten in Zwitserland behandelt. Hermann Leuenberger wijdt een beschouwing aan de houding van de vakbonden tegenover de vreemdelingen. Het nummer wordt besloten met een artikel van Hardi Fischer over de voorlopige resultaten van een sociologisch onderzoek van de „Forschungsstelle für Arbeitspsychologie" der "Eidgenössischen Technischen Hochschule" te Zürich met betrekking tot de mate van assimilatie van de buitenlandse arbeiders.

Ba VII - 1

Industrielle Organisation, $1961, n$ r. 6

E 224.0

\section{Vraagstukken op het terrein der ,industrial relations", een terreinverkenning}

L u l of s, D r. J. G. - De vraagstukken op het terrein van de industriële betrekkingen liggen op het grensgebied van economie, sociologie, sociale psychologie, rechtswetenschappen en, in sommige gevallen, op dat van de politieke wetenschappen. Het is opmerkelijk dat - afgezien van belangwekkende incidentele studies veelal verricht door historici of juristen - de verschijnselen op het gebied der industriële betrekkingen in ons land zelden in hun onderlinge samenhang als een zelfstandig probleemgebied wer- 
den benaderd. In het buitenland worden de vraagstukken der industriële betrekkingen reeds tientallen jaren bestudeerd, hetgeen in de Verenigde Staten ertoe heeft geleid dat aan vrijwel alle vooraanstaande universiteiten een instituut voor industriële betrekkingen werd opgericht. Kenmerkend voor deze academische instellingen is de nauwe samenwerking van in verschillende richting gespecialiseerde economen met sociologen en psychologen en het nauwe contact dat wordt onderhouden met werkgevers- en werknemersorganisaties.

De vraagstukken op het gebied der ,industriële betrekkingen" houden verband met het systeem van industriële betrekkingen, dat in iedere geïndustrialiseerde maatschappij kan worden onderkend en dat men moet opvatten als een deelsysteem van de maatschappij, dat als zodanig voor analytische doeleinden wordt onderscheiden. In navolging van Dunlop (,Industrial Relations Systems") onderscheidt de schrijver in dit systeem: bepaalde subjecten, een bepaalde context, een waarderingssysteem, dat het geheel samenbindt en een geheel van regels.

$\mathrm{Na}$ deze terreinafbakening behandelt de schrijver o.a. enkele aspecten van de ontwikkeling der ,industriële betrekkingen" in Nederland. Aan het artikel is een appendix toegevoegd, waarin de begrippen functie en structuur worden behandeld.

Sociaal Maandblad Arbeid, 25 april 1961

E 224.0

\section{Winstaandeel en economische groei}

Witteveen, Prof. Dr. H. J. - Op grond van een analyse van het partieel oligopolie stelt de auteur, dat het winstaandeel in een partieel- oligopolistische bedrijfstak afhankelijk is van het verschil in kostenniveau tussen de marginale en de intramarginale ondernemingen. Deze kostenverschillen worden o.a. veroorzaakt door het verschil in de efficiëntie van de organisatie en in de samenwerking met de wergnemers; een grote onderneming $k a n$ met een team van specialisten werken en daardoor een zekere voorsprong krijgen. Een andere bron van kostenverschillen zijn de ongelijke besparingen, die voortvloeien uit produktie of verkoop op grote schaal. De belangrijkste oorzaak van verschil in kosten is echter de mate, waarin verschillende ondernemingen de technische vooruitgang meemaken, en wel met name in hoeverre zij bij de investeringen werkelijke vernieuwingen doorvoeren, welke concurrenten, die te zelfder tijd investeren nog niet toepassen. $\mathrm{Na}$ een zekere periode zullen de marginale ondernemers tot navolging overgaan. Blijft de navolgingsperiode gelijk, dan zal het kostenverschil tussen intra-marginale en marginale ondernemingen derhalve direct afhankelijk zijn van het tempo der technische vooruitgang.

Vervolgens betoogt de auteur, dat ook onder andere marktvormen dan het partiëel oligopolie een zekere samenhang tussen technische vooruitgang en winstaandeel bestaat, zodat gesteld $\mathrm{kan}$ worden dat er voor het economisch leven als geheel een zekere macroeconomische samenhang tussen winstaandeel en technische vooruitgang is. Deze samenhang maakt het moeilijk om het arbeidsaandeel ten koste van het winstaandeel te vergroten zonder de economische groei te schaden. De overheidspolitiek zal er zich toe moeten beperken de redelijke concurrentie tussen marginale en intra-marginale ondernemingen te stimuleren. Alleen door een dergelijke politiek $k$ an het winstaandeel zonder gevaar voor de economische groei worden beperkt in die zin dat een ongemotiveerde stijging van de prijs boven de kosten van de marginale ondernemingen kan worden voorkomen.

Ba VII - 4

De Economist, maart/april 1961

E 212.1

\section{Herhaalarbeid}

A l b in sk i, D r. M. - Over de gevolgen van herhaalarbeid voor de arbeiders lopen de meningen uiteen. Verschillende schrijvers wijzen op nadelige gevolgen zoals het verloren gaan van geestelijke beweeglijkheid, wilskracht en ambitie. De belangstelling van de arbeider voor het werk en het bedrijf en zelfs voor gebieden van het leven welke daar buiten liggen vermindert. Hij kan geen voldoening vinden in het werk en zoekt in zijn vrije tijd oppervlakkige verstrooiïng. Anderen en dit zijn veelal mensen die zich op praktijkervaring beroepen betogen dat een groot deel van de arbeiders niet anders dan herhaalarbeid wenst. De doorsnee-arbeider wil zich niet voor het bedrijf inzetten en initiatief en verantwoordelijkheidszin zijn hem vreemd.

Een literatuurstudie leerde de schrijver, dat, ofschoon op grond van de verrichte onderzoekingen nog geen duidelijke conclusies kunnen worden geformuleerd, er aanwijzingen zijn dat herhaalarbeid ongunstige gevolgen kan hebben. De gevolgen zijn niet voor alle mensen dezelfde. Van betekenis is het geheel van omstandigheden waarin 
de arbeider verkeert. Een diepgaand onderzoek naar de gevolgen van herhaalarbeid is behalve uit wetenschappelijk gezichtspunt ook uit ethische en economische overwegingen gewenst.

Automatisering van de produktie zal niet binnen afzienbare tijd tot opheffing van herhaalarbeid leiden. De concurrentie zal de bedrijven die nog niet aan automatisering toe zijn dwingen tot een verder gaande taaksplitsing. Bovendien ontstaan door de automatisering op het gebied van de contrôle van het produktieproces nieuwe taken zonder geestelijke inhoud.

Ba VII - 5

E 641.213 .45

Economisch-Statistische Berichten, 19 april 1961

\section{The human problems of shift operation}

$\mathrm{R}$ e id, $\mathrm{P}$ e t e r C. - Voor 4 miljoen werknemers in de Verenigde Staten is de werkdag een werknacht. Zelfs op de kantoren komt nachtarbeid voor. Uit een recent onderzoek van levensverzekeringsmaatschappijen bleek, dat 21 van de 31 onderzochte ondernemingen met nachtploegen werkten ten einde hun electronische rekenapparatuur intensiever te kunnen benutten en zodoende de kosten te verlagen.

Nachtarbeid stelt zeer specifieke eisen aan de werknemer: het doet zijn levensritme zeer sterk afwijken van dat van zijn sociale omgeving; wanneer hij van de nacht- in de dagploeg of omgekeerd overstapt moet hij zijn eet- en slaapgewoonten veranderen en dit schijnt ook biologisch gezien een ingrijpende verandering te zijn. Om aan deze laatste bezwaren tegemoet te komen is wel eens voorgesteld de werktijden van de ploegen iedere dag 20 minuten op te schuiven zodat dan een meer geleidelijke overgang wordt bereikt.

Voor het bedrijf is het belangrijkste vraagstuk hoe de moraal van de nachtploeg op peil te houden. De hogere beloning is hiertoe niet steeds voldoende. Een ander middel is de nachtploeg samen te stellen uit mensen met een verschoven slaap-waak-ritme.

Een ander vraagstuk is de samenwerking tussen de ploegen; er ontstaat gemakkelijk een vijandige verhouding tussen de nacht- en de dagploeg. Het is vooral de werkbaas, die voor een goede verstandhouding moet zorgen, mede door contact op te nemen met zijn collega's.

Ba VII - 6

E 641.214

The Manager, april 1961

\section{Belegging in aandelen door pensioenfondsen (slot)}

$\mathrm{B}$ rands, Prof. J. - In dit tweede deel van zijn artikel over belegging in aandelen door pensioenfondsen bespreekt de schrijver de mogelijkheden voor een verdere ontwikkeling van de ouderdomsvoorziening. Het kapitaaldekkingsstelsel schiet te kort bij waardedaling van het geld. De meest logische oplossing zou zijn een algemeen omslagstelsel voor de gehele bevolking, doch de ontwikkeling van het levensverzekeringbedrijf en talloze bedrijfspensioenfondsen heeft in een bepaalde richting geleid welke niet scherp kan worden omgebogen. Van de totale beleggingen van de bedrijfs- en pensioenfondsen is slechts een klein gedeelte in aandelen belegd. Verschillende auteurs bevelen aan een groter deel van de middelen dan thans het geval is in aandelen te beleggen. Weliswaar kan dan geen vaste uitkering in guldens worden gegarandeerd, doch het is waarschijnlijk dat de uitkeringen in vergelijking tot de stortingen niet al te zeer in koopkracht zullen zijn gedaald.

Een groot gedeelte van de pensioengerechtigden is thans tevreden met een vaste uitkering in guldens. Het is de schrijver evenwel gebleken, dat vele pensioengerechtigde functionarissen boven een vaste uitkering in guldens prijs stellen op een additionele meer waardevaste uitkering. Het is te verwachten dat geleidelijk een verschuiving naar belegging in de risicodragende sfeer zal optreden. Een belangrijke vraag is of de kapitaalmarkt voldoende ruimte zal bieden voor een sterk toenemende vraag naar aandelen. De behoefte aan risicodragend vermogen echter groeit en indien nodig kan ook van buitenlandse kapitaalmarkten gebruik worden gemaakt.

De schijver stelt zich een gelaagde ouderdomsvoorziening voor: de waardevaste A.O.W. als basis, daarboven een vaste uitkering in guldens van een pensioenfonds of levensverzekeringmaatschappij en daarboven een uitkering uit een met de ontwikkeling van de bedrijvigheid groeiend fonds.

Ba VII - 9 Tïdschrift voor Vennootschappen, Verenigingen en Stichtingen, april 1961 E 313.1 